\title{
Coordenação e Coesão em Grupos de Comercialização de Etanol da Região Centro-Sul do Brasil
}

\author{
Dalton Siqueira Pitta Marques ${ }^{1}$ e Luiz Fernando de Oriani e Paulillo²
}

\begin{abstract}
Resumo: Um dos principais reflexos do período pós-desregulamentação do setor sucroalcooleiro foi a criação de grupos de comercialização de etanol, uma estratégia das usinas para se defender do poder de barganha das distribuidoras de combustíveis que impuseram à época condições de preço bastante desfavoráveis ao segmento de produção de etanol. A dificuldade de coordenação, porém, sempre foi característica do setor sucroalcooleiro, o que levanta dúvidas sobre o sucesso dos grupos em coordenar as vendas e manter a coesão. Partindo-se desse ponto, este trabalho tem por objetivo analisar a coordenação e a coesão de grupos de comercialização de etanol atuantes na região Centro-Sul do Brasil. Para isso, conduziu-se um estudo de casos múltiplos, sendo analisados três dos quatro grupos de comercialização atuantes na região Centro-Sul. Ao final, concluiu-se que, embora problemas de coordenação existam, os grupos, cada qual com suas características, dando maior ou menor importância para questões econômico/ contratuais e relacionais, são bem-sucedidos e permitem melhora no poder de barganha junto às distribuidoras de combustível.
\end{abstract}

Palavras-chaves: Coordenação, coesão, setor sucroalcooleiro, grupos de comercialização.

Abstract: One of the major consequences of the deregulation period in the sugar and ethanol industry was the creation of ethanol trading groups. Ethanol producers adopted this strategy to defend themselves against the market power of fuel distributors, which, at that time, imposed very unfavorable price conditions to the production segment. However, coordination problems have always been a characteristic of this industry, which raise doubts about the success of the trading groups to coordinate sales and maintain group cohesion. Based on this point, this paper aims to examine the coordination and cohesion of ethanol trading groups. For this purpose, a multiple case study was conducted, with three of the four trading groups operating in the Central-Southern region in Brazil. The

1 Doutor em Engenharia de Produção pela UFSCar. Professor de Pós-Graduação da Faap Campus Ribeirão Preto. E-mail: daltonspm@yahoo.com.br

2 Pos-doutorado na FAO-ONU em Economia, Agroenergia e Políticas Públicas. Professor do Departamento de Engenharia de Produção da Universidade Federal de São Carlos e do Programa de Pós-graduação em Gestão da Produção da UFSCar. E-mail: dlfp@power.ufscar.br 
conclusion was that although there are coordination problems, groups, each of them with their characteristics, are successful and allow to balance the power game between manufacturers and distributors.

Key-words: Coordination, cohesion, sugar and ethanol industry, trading groups.

Classificação JEL: L, L1, L14.

\section{Introdução}

Alguns dados mostram a importância do setor sucroalcooleiro para a economia brasileira. Em 2010, eram 434 indústrias de processamento de cana-de-açúcar. Dessas, 168 produzem somente álcool, 16, somente açúcar e 250 são mistas (MAPA, 2010). A produção está concentrada na região Centro-Sul do Brasil, sendo que o estado de São Paulo conta com 199 unidades. O etanol também assume papel estratégico na matriz energética nacional. Segundo a ANP (Agência Nacional do Petróleo), no primeiro semestre de 2008, pela primeira vez o consumo somado de álcool anidro e hidratado se igualou ao consumo de gasolina (OLIVEIRA, 2008). Esse crescimento foi suportado por uma expansão recorde do setor: mais de 100 novas usinas entraram em operação entre 2005 e 2009 (MILANEZ et al., 2010). Com a crise econômica internacional de 2008 e 2009, porém, os investimentos foram freados, resultando, no início da década de 2010, em um desequilíbrio entre o ritmo da demanda (cada vez maior devido aos carros bicombustíveis) e da oferta.

Fazendo uma retrospectiva do setor, constata-se que momento crucial foi sua desregulamentação. Essa desregulamentação foi gradual, tendo suas bases na crise do Estado na década de 1980 (que reduziu a capacidade de regulação do governo brasileiro), passando pela extinção do Instituto do Açúcar e do Álcool (IAA) em 1990, e culminando na liberação dos preços da cana, do álcool e do açúcar em 1999. A gradualidade deste processo é explicada pelas dificuldades de se equilibrar questões econômicas, ambientais e sociais (MELLO e PAULILLO, 2003, p. 8).

Mesmo gradual, porém, o processo não deixou de ser traumático para as usinas: com o livre mercado, eram mais de 300 usinas, para cinco grandes distribuidoras, resultando, a partir do jogo de forças do mercado, em grande depreciação de preços (VIAN, 2003). A iniciativa criada pelas usinas à época da desregulamentação foi a criação da Brasil Álcool e da Bolsa Brasileira de Álcool (BBA). Uma era responsável pelos estoques e a outra, pela comercialização. Assim, à época, concentraram $85 \%$ do álcool combustível produzido no Centro-Sul (MARJOT-TAMAISTRO e BARROS, 2002, p. 8). Embora tenha atingido o objetivo de elevar os preços do etanol, essa iniciativa não perdurou. Dificuldades de coordenação entre as diversas usinas associadas (muitas usinas não cumpriam os acordos e vendiam direto ao mercado)e a decisão do Conselho Administrativo de Defesa Econômica (Cade), considerando que se caracterizava um cartel, levaram à extinção em 2000 (VIAN, 2003; BACCARIN, 2005).

A iniciativa, porém, frutificou na criação de três grupos (SCA, Bioagência e CPA) e no fortalecimento da Copersucar, já atuante. Lopes (2009, p. 64) afirma que essas experiências mostraram aos produtores que podiam trabalhar juntos e que o custo de se manter uma área voltada apenas para a comercialização poderia ser diluído com outras unidades. Segundo Vian (2003, p. 184), este foi um dos fatos mais importantes do período posterior à desregulamentação, caracterizado pela união de empresários "para reduzir custos 
e vender álcool a preços mais competitivos". O estudo específico dos grupos de comercialização foi, aliás, uma das sugestões de trabalhos futuros de Lopes (2009, p. 103). A autora afirma que a utilização do método de estudo de caso permitiria a identificação, com maior profundidade, dos arranjos entre usinas e grupos de comercialização. Conforme será discutido posteriormente, é o que se faz neste trabalho.

Embora a criação de grupos de comercialização possa aumentar o poder de barganha frente a distribuidores, Azevedo (2001) afirma que muitas vezes associações desse tipo não perduram, em virtude de a coordenação ex-post exigir altos incentivos para cumprimento das regras, aumentando, desta forma, os custos de transação. Assim, estabelece-se como objetivo desta pesquisa, justamente, analisar a coordenação e a coesão de grupos de comercialização de etanol atuantes na região Centro-Sul do Brasil. Ao avaliar esses pontos, espera-se, também, verificar se os grupos são bem-sucedidos em melhorar as condições de negociação com as distribuidoras.

A dissolução, em 2011, da Allicom, criada em 2008, e a dificuldade em concretizar o grupo Brasil EBC, criado em 2009, mas ainda pouco atuante, ilustramas dificuldades de coordenação dos grupos. Conforme afirma Vian (2003, p. 107), o desencontro e o oportunismo são características da dinâmica do complexo canavieiro. Ainda que as relações entre os industriais tenham se intensificado com a criação dos grupos de comercialização, esses têm demonstrado um baixo esforço para solucionar problemas de longo prazo e melhorar a imagem do setor como um todo (PAULILLO, VIAN e MELLO, 2008). Para Mello (2004), o setor sucroalcooleiro tradicionalmente demonstra ter um baixo envolvimento dos seus atores em esforços que melhorem as condições institucionais. Momentos de engajamento mais expressivos acontecem principalmente em períodos de crise setorial, como o que resultou na formação da BBA e da Brasil Álcool. Porém, passada a crise, os atores retomam comportamentos individualistas.

O tema da coordenação tem especial interesse no âmbito do agronegócio ao considerar a tendência, nos últimos anos, de estreitamento das relações entre as diversas etapas produtivas. Uma grande variedade de estruturas de governança tem sido utilizada pelos agentes de algumas cadeias, fazendo com que transações exclusivamente via mercado sejam menos frequentes (MELLO, 2008; ZYLBERSZTAJN, 1995). No setor sucroalcooleiro, os grupos de comercialização, com associação horizontal das usinas, para realizar conjuntamente algumas atividades, permitem vislumbrar a existência de redes de empresas para governar as transações. Em redes, conforme Powell e Smith-Doerr (1994), a competição não mais ocorre no nível de empresas, mas entre alianças de empresas, que podem cooperar entre si em um projeto, mas competir em outro.

Desta forma, este trabalho buscou na Sociologia Econômica as bases para a construção do referencial teórico, focando na temática de análise das relações em redes de empresa. Também foram buscadas referências nas Ciências Sociais, de modo a permitir melhor compreensão sobre o conceito de coesão. Conforme Marchi e Wittmann (2008), abordagens multidisciplinares podem contribuir para uma maior compreensão das redes empresariais, especialmente se aproximarem fatores sociais e comportamentais com o desempenho dessas redes.

Para Sauvée (1995), as incertezas do ambiente, somadas às informações incompletas e ao oportunismo dos agentes, fazem com que a escolha de uma forma de governança não possa ser entendida somente a partir dos custos, de maneira determinística. Ao se considerar, além dos fatores econômicos, fatores como a lealdade, a confiança e o comprometimento, é possível maior compreensão sobre como os agentes tomam suas decisões e o que influencia na melhor forma de coordenação. Ménard (2005) reforça que uma explicação clara e satisfatória de por qual motivo e sob quais circunstâncias uma forma de organização ou governança se sobrepõe a outra exige investigações sobre as características internas desses arranjos. Há, ainda, na visão do autor, a necessidade de mais estudos empíricos que identifiquem variáveis capazes de analisar o 
papel da incerteza e de outros fatores humanos sobre as formas de governança.

A seguir, na fundamentação teórica, faz-se primeiramente uma apresentação mais detalhada sobre os grupos de comercialização no contexto do setor sucroalcooleiro para, em seguida, discutir a coesão e coordenação de redes de empresas, bem como indicadores para avaliá-los. Posteriormente, são apresentados os métodos da pesquisa de campo. No item seguinte, são discutidos os resultados dos três estudos de caso realizados, finalizando o trabalho com as conclusões.

\section{Fundamentação teórica}

\subsection{Os grupos de comercialização de etanol}

Embora após a desregulamentação tenha se acentuado um movimento de fusões e aquisições no setor sucroalcooleiro, a produção ainda é altamente pulverizada, segundo Farina et al. (2010). O HHI (Herfindahl-Hirschman Index), índice comumente usado para medir a concentração, calculado pelos autores para o ano de 2008 para as usinas de São Paulo, foi baixo, com valor de 270 . O número equivalente (número de empresas de igual tamanho que gerariam o mesmo HHI) foi de 37, também indicando uma baixa concentração. No segmento de distribuição, o HHI calculado pelos autores, mesmo maior do que para o de produção (valor de 951, com número equivalente de 11 empresas), também não foi elevado. Entretanto, Farina et al. (2010, p. 242) destacam que parte dos usineiros não vende para muitas distribuidoras emergentes por razões ligadas à inadimplência e sonegação fiscal. Assim, os autores optaram por calcular o HHI considerando apenas as distribuidoras do Sindicom. O resultado foi um HHI alto, superior a 1.800. Além disso, é preciso lembrar que, em 2008, à época da pesquisa, ainda não havia ocorrido a aquisição da Chevron pela Ipiranga, nem a fusão entre Esso/Cosan e Shell, resultando em ainda maior concentração no segmento de distribuição. Por mais que entre 2008 e 2011 também tenham ocorrido aquisições no setor de produção de etanol, o impacto no mercado foi bem menor do que o dessas fusões no setor de distribuição. Em 2009, BR, Esso/Cosan, Shell e Ipiranga respondiam por $57 \%$ do etanol distribuído no País.

Pelo menos em termos de participação de mercado, os dados dão indícios de que os grupos conseguem trazer mais equilíbrio ao mercado. Embora não haja dados para 2009, na safra 2006/2007, juntas, as unidades produtoras que fazem parte de Bioagência, CPA, SCA e Copersucar foram responsáveis por 51,5\% do álcool comercializado no Centro-Sul do Brasil (DOLNIKOFF, 2008). Abaixo, faz-se uma explanação, com dados coletados a partir de pesquisa bibliográfica e documental, sobre cada um desses grupos.

A SCA (Sociedade Corretora do Álcool) tem a maior participação dentre os grupos de comercialização. Ela é uma empresa que oferece aos seus associados o serviço de operacionalização das vendas. Ela realiza as vendas na medida em que é solicitada para tal por seus associados. Além disso, ela fornece informações mercadológicas para subsidiar as decisões de seus associados, que ocorrem individualmente. Também parte das unidades a decisão entre vender no mercado spot ou firmar contratos com as distribuidoras (DOLNIKOF, 2008). Ao contrário do apresentado por Dolnikoff, porém, a SCA tem sim, pelo menos contratualmente, a exclusividade da comercialização de suas associadas (MORI e MORAES, 2007). Em 2010 eram 63 unidades associadas ao grupo (SCA, 2010).

A Copersucar constitui-se em uma cooperativa, composta atualmente por 38 usinas (COPERSUCAR, 2010), tendo sido fundada ainda na década de 1950. As unidades cooperadas têm a obrigação de fornecer toda sua produção à cooperativa. É ela quem negocia as vendas e firma os contratos junto às distribuidoras. É também a Copersucar quem toma a decisão sobre o momento da venda e se por mercado spot ou contrato (DOLNIKOFF, 2008). A Copersucar se diferencia dos outros grupos à medida que comercializa também a produção de açúcar dos 
cooperados e que tem extensa infraestrutura logística e escritórios no exterior. Em 2011, por exemplo, foi anunciada uma associação com a corporação árabe JamalAl-Ghurair (JAG), para a criação de uma empresa de fretamento marítimo, que pode resultar, posteriormente, na criação de uma joint venture para refino de açúcar e armazenamento e venda de açúcar e etanol no Oriente Médio (RELATÓRIO RESERVADO, 2011).

Segundo Dolnikoff (2008) a Bioagência atuaria exclusivamente na comercialização via mercado spot. Informações obtidas no setor, porém, indicam que ela também intermedia os contratos firmados entre usinas e distribuidoras. A Bioagência constitui-se em uma empresa, prestadora de serviços, que tem estrutura interna de mesa de operações para articular a venda de seus associados. A decisão sobre o momento da venda parte sempre dos associados, que recebem informações mercadológicas da coordenadora do grupo. Em 2010, eram 29 as unidades associadas (BIOAGÊNCIA, 2010).

Segundo Dolnikoff (2008), a CPA também teria exclusividade na comercialização de toda a produção de etanol seus acionistas. A CPA é uma empresa independente, cuja propriedade é de seus associados. Porém, além de vender a produção de seus associados, ela comercializa a produção de algumas outras unidades, denominadas "representadas". Em 2010, eram 16 as usinas acionistas (CPA, 2010), que podem utilizar, também, a estrutura de armazéns do grupo, localizada na região de Maringá (PR), e o escritório voltado a exportações, localizado nas Ilhas Virgens. Não há informações na literatura se a decisão de venda é da coordenadora do grupo ou das usinas.

\subsection{Coordenação e coesão em redes de empresas}

Para entender os mecanismos de coordenação e coesão em redes de empresas, convém discutir primeiramente como elas surgem e evoluem. Larson (1992) sugeriu um ciclo para explicar a evolução das redes. Após estudar uma amostra de empresas e as relações sistemáticas e entre pares dessas empresas, o autor propôs um ciclo composto por três fases. A primeira fase é quando se estabelecem as pré-condições para o intercâmbio. É preciso que relacionamentos pessoais e reputações conhecidas reduzam a incerteza e criem a expectativa de que haverá cooperação entre as organizações. Sem esses aspectos, dificilmente a rede se concretiza. A segunda fase estabelece as condições necessárias para construção do relacionamento. Ainda que os benefícios econômicos sejam importantes, nessa fase de experiência, o controle obtido na rede é resultado do crescimento da confiança e da evolução das normas de reciprocidade, tendo normalmente um dos parceiros como estimulador. $\mathrm{Na}$ terceira fase, as organizações se tornam operacionalmente e estrategicamente mais integradas. $\mathrm{O}$ controle e a coordenação efetiva são atingidos e o oportunismo é evitado por meio da presença de obrigações morais, confiança e preocupação em preservar reputações.

A partir do estudo de Larson (1992), Assens (2003) também propõe um ciclo de evolução das redes. Neste ciclo, a primeira fase corresponde à formação da rede, a partir do núcleo de fundadores. $\mathrm{O}$ núcleo de fundadores é estabelecido por meio de trocas recorrentes e experiências recíprocas de colaboração, sendo a reputação dos fundadores fundamental para reduzir as incertezas e passar confiança aos novos membros. Uma ordem coletiva emerge progressivamente e de maneira nãoprogramada. A segunda fase corresponde à expansão das fronteiras da rede, a partir da adesão de novos membros. A rede cresce pela chegada de membros cooptados pelos membros mais antigos, que, por consequência, aumentam sua área de influência. Isso faz com que, no curto prazo, os membros apadrinhem novas empresas para que entrem no grupo. No longo prazo, porém, cria a necessidade de integrar esses novos membros para garantir a coesão da rede, pois, quanto mais a rede cresce, mais aumentam os problemas de coordenação e controle. Assim, a partir de certo momento, pode ser necessário limitar o crescimento para preservar a coesão. A terceira fase corresponde à maturidade da rede, com consolidação das relações e o adensamento das 
ligações entre os membros. Se houver crescimento excessivo da rede, como já dito, problemas podem surgir, restando aos membros algumas alternativas: ou aceitam as regras colocadas pelos membros mais influentes, com o risco de evolução para uma organização piramidal, que serve aos interesses dessas empresas-piloto; ou se opõem a uma evolução mais formal da rede, diminuindo sua participação nas trocas e no compartilhamento de recursos e até abandonando-a. À medida que as fronteiras da rede se rompem, há o seu desaparecimento, com a criação de uma forma de organização mais fragmentada, baseada na desconfiança.

Dessa forma, a evolução da rede e seu tamanho são fatores importantes para o sucesso ou fracasso de uma rede. Se, por um lado, quanto mais uma rede se expande, mais difícil torna-se sua gestão, em virtude do número crescente de elementos em interação; por outro lado, se a rede para de se desenvolver, pode surgir uma rigidez das ligações, o que também traria problemas, provocando, inclusive, a saída de alguns membros. Além da expansão, outra questão colocada por Assens (2003) como problemática para o sucesso de uma rede é o balanceamento entre autonomia individual e controle coletivo. Privilegiar a autonomia sem se preocupar com o controle estimula a criatividade e favorece o engajamento das pessoas; mas a autonomia mal controlada pode dar espaço para conflitos de interesse e contradições coletivas. Por outro lado, enfatizar o controle em detrimento da autonomia melhora a coordenação coletiva e a coesão; entretanto, limita a capacidade de adaptação e reação individual. Assim, é preciso conciliar duas dimensões antagônicas: autonomia e interdependência. Por isso, é fundamental estudar os princípios da coesão dentro da rede, que significa estudar "a harmonia das trocas, a compatibilidade de elementos e as regras de comportamento dentro da estrutura" (ASSENS, 2003, p. 53).

Dessa forma, entende-se que avaliar a coesão é fundamental para entender a organização de uma rede e suas possibilidades de sucesso. Para analisar redes, porém, a literatura tradicionalmente se concentrou na caracterização das estruturas das redes. Segundo Britto (2002), quatro elementos morfológicos básicos normalmente são considerados: nós, posições, fluxos e ligações. Os nós, conforme já citado, referem-se às empresas ou atividades desenvolvidas dentro das redes. As posições tratam da divisão do trabalho dentro da rede. Os fluxos referem-se a fatores tangíveis (bens) e intangíveis (informações) que circulam na rede. As ligações correspondem às transações entre as empresas, que podem resultar em maior ou menor centralidade e densidade. A centralidade corresponde ao grau em que cada empresa está envolvida com as ligações, ou seja, refere-se ao número de ligações associadas a um nó particular. Redes com alta centralidade tendem a ter um ator dominante, capaz de influenciar os demais (BRITTO, 2002; SILVA e COSER, 2006). Já a densidade equivale à proporção do número de ligações observadas em uma rede com relação ao número total de ligações possíveis (SACOMANO NETO, 2003). A coesão tem grande relação com a densidade. Porém, é preciso diferenciá-las: a densidade é uma variável da estrutura da rede; enquanto a coesão é uma variável das relações. Assim, pode-se, por exemplo, ter uma rede difusa (baixa densidade), com forte coesão (SACOMANO NETO, 2003).

Assim, as estruturas da rede não devem ser os únicos aspectos considerados. No caso dos grupos de comercialização, em que a empresa coordenadora já assume um papel de centralidade e há tanta incerteza quanto ao comportamento dos agentes, entender as relações passa a ser ainda mais importante. Sacomano Neto e Truzzi (2004, p. 258) afirmam que nas relações podem-se observar aspectos como poder, confiança ou oportunismo, controle social, sistemas de alinhamento de interesses, formas de negociação, entre outros aspectos. Para Friedkin (2004), os processos sociais têm grande importância em determinar as atitudes e comportamentos dos indivíduos e, consequentemente, a coesão.

Para avaliar redes organizacionais, por vezes os autores buscam na sociologia referências que ajudem na compreensão do conceito de coesão. 
É o que se faz aqui. Filgueira (2007) afirma que a ideia de coesão social é acusada de ambígua e abstrata, pela dificuldade de ampará-la em indicadores concretos. Apesar disso, a ideia sobrevive, pois seu grande mérito está em colocar no centro de análises o problema da ação cooperativa. Seja no mercado, seja em pequenas comunidades, a existência de um quadro normativo compartilhado é imprescindível para produzir interações sociais positivas e para que os indivíduos possam orientar sua ação a partir das expectativas de ação do outro.

$\mathrm{O}$ sentido de pertencimento à sociedade (ou grupo) é outro ponto central nas diversas definições de coesão social. Um alto grau de coesão existe em grupos em que os vínculos que ligam os indivíduos ao grupo são fortes e os valores que regem as ações coletivas são amplamente aceitos pelos membros (CEPAL, 2007).

Ao analisar o problema da coesão social para os povos da América Latina, Filgueira (2007) argumenta que crises de coesão social ocorrem quando interações inevitáveis carecem de normas adequadas. Quando em um mesmo território convivem diferentes indivíduos e grupos, a interação, em algum nível, se torna inevitável. Foi com os movimentos migratórios, quando diferentes se viram obrigados a negociar, cooperar, enfrentar e resolver conflitos, que a coesão social tornou-se um problema. Da mesma forma, é com a formação e crescimento dos grupos de comercialização de etanol: quando diferentes empresas se viram obrigadas a interagir, que se tornou necessário estudar a coesão dentro dos grupos.

Para Sacomano Neto e Truzzi (2004, p. 258), “a coesão das relações é uma propriedade relacional dos pares de atores de uma rede e pode ser compreendida pela intensidade do relacionamento (forte ou fraca), estratégia de saída ou diálogo, relações de longo prazo, etc.".

Uzzi (1997) buscou uma explicação para a relação entre aspectos sociais, o processo microcomportamental de tomada de decisão e os resultados econômicos dentro do contexto de redes organizacionais. $\mathrm{O}$ autor trabalhou bastante com o conceito de embeddedness, analisando as propriedades de relações imersas (embedded) e de que forma elas criam vantagens competitivas para empresas e redes de empresas. Na visão do autor, as relações imersas são aquelas em que há confiança, solução conjunta de problemas e informações privilegiadas e apuradas. Assim, além de manifestada no comportamento de seus membros, uma rede com forte coesão seria mais eficaz no alcance de seus objetivos (PAULILLO et al., 2009).Torna-se mais fácil controlar e prever o comportamento dos atores quando há confiança e reciprocidade. Há mais chances de ocorrer coordenação e controle social entre os atores.

Porém, é preciso precaução nas análises. Marchi e Wittmann (2008, p. 24) identificaram que não necessariamente a rede na qual seus membros estão mais comprometidos, cooperam mais e têm mais confiança uns nos outros é aquela que alcança os melhores resultados. Isto ocorre pois, quando uma rede se apresenta muito coesa e internamente fechada, cria-se uma situação de clausura. A clausura ocorre quando há pouca ou nenhuma conexão externa ou quando essas conexões externas são redundantes. Pesquisa realizada por Sacomano Neto (2003, p. 6) corrobora essa afirmação: "maior coesão e densidade permitem a troca de informações refinadas, reciprocidade, normas cooperativas, etc.; entretanto, [...] podem dificultar o acesso desses atores a novas informações que circulam fora daquele ambiente restrito".

Os problemas do excesso de coesão também foram identificados por Gargiulo e Benassi (2007). Embora o estudo não tenha sido realizado com redes de empresas, mas sim com equipes de funcionários dentro de empresas, os autores identificaram que, ao longo do tempo, a coesão prejudica as possibilidades de novos relacionamentos cooperativos com pessoas de fora. A mesma coesão que previne comportamentos oportunistas diminui a capacidade de adaptação, criando um trade-off entre segurança e flexibilidade.

Como já afirmado, a coesão é uma propriedade relacional dos atores de uma rede. 
Porém, ela não será medida aqui a partir de cada transação entre cada ator; mas sim a partir de uma perspectiva geral dos atores sobre o grupo e suas relações. Acredita-se que ela possa ser compreendida ao se analisar a intensidade do relacionamento, a atitude, a reputação, a duração das relações e se as empresas optam pelo diálogo ao invés da estratégia de saída. Não há, porém, na literatura, consenso sobre a forma de se medir coesão social. Assim, diferentes indicadores são usados, conforme discutido abaixo.

Segundo Friedkin (2004, p. 410), grupos são coesos quando as condições do grupo produzem atitudes e comportamentos positivos dos membros deste grupo e, ao mesmo tempo, quando as interações entre os membros do grupo operam para manter essas mesmas condições. Para Friedkin (2004), indicadores de coesão social, tomando-se por base o indivíduo, incluem: as atitudes dos membros do grupo (como o desejo ou a intenção de permanecer no grupo e a identificação com o grupo ou sua lealdade ao mesmo); e os comportamentos individuais dos membros do grupo (como a decisão de desfazer, enfraquecer, manter ou fortalecer sua participação no grupo, sua suscetibilidade à influência interpessoal e outros indicadores de comprometimento). Dessa forma, o autor defende que, para analisar a coesão de um grupo, deve-se focar nas atitudes e nos comportamentos de seus membros. Ele se justifica dizendo que a maioria das manifestações agregadas da coesão de um grupo (como taxa de turnover e proporção de membros contribuindo para tarefas do grupo) é resultado das atitudes e comportamentos de seus membros. Segundo o autor, ainda que diferentes pesquisadores enfatizem diferentes indicadores de coesão no nível do indivíduo, há muita proximidade teórica entre esses indicadores, pois lidam com a atração ou conexão com o grupo. Assim, eles devem ser tratados como diferentes dimensões nas quais a coesão se manifesta. Um foco exclusivo em um desses indicadores seria muito restritivo.

A questão do desejo de manter ou fortalecer a associação no futuro é um item importante de análise. Segundo Powell e Smith-Doerr (1994), quando essa possibilidade existe, as pessoas não apenas estão mais dispostas a cooperar, como também desejam punir os desertores. Quando as partes reconhecem que têm objetivos comuns, as relações de cooperação mais prontamente acontecem. Além do mais, o monitoramento é mais natural e fácil se realizado pelos pares e não por supervisores. Friedkin (2004) afirma, também, que estudos sobre coesão social não deveriam ignorar os efeitos sobre a rede de diferenças interpessoais e da perda ou adição de membros. São processos de autorregulação que permitem a alguns grupos manter altos níveis de coesão social mesmo sob circunstâncias adversas e de mudança.

Garcia (2011, p. 63), baseado em trabalho de Sacomano Neto e Truzzi (2005), lista os seguintes mecanismos como importantes para a coesão: vínculos anteriores e duração das relações; mecanismos de resolução de problemas; frequência da interação; intensidade emocional (refletida em relações de amizade, participação em eventos sociais e disponibilidade de assumir riscos sem temer consequências negativas); confiança; reciprocidade; reputação; comprometimento com recursos (realização de investimentos conjuntos); velocidade na resolução de problemas e difusão de informações e grau de formalidade.

Paulillo et al. (2009) ao avaliarem a coesão social de uma rede do projeto Viva Leite, do governo do estado de São Paulo, optaram por fazê-lo analisando-se atributos dos atores e das relações. Os atributos dos atores foram: agilidade; reputação; esforço para manutenção de atores; esforço para novas opções ou ganhos e cooperação. Os atributos das relações foram: comunicação; regras e uso; centralidade; controle e frequência. Tão mais coesa seria a rede, quão maior fossem as notas que os atores dessem para cada um dos atributos acima citados. A justificativa para análise de atributos dos atores e das relações residiu no fato de que a intensidade do poder de barganha de cada ator começa a se definir a partir de características individuais como reputação, informação, habilidade de negociar etc. Porém, as conexões de cada rede também influenciam 
a desigualdade de poder entre os atores, através de regras, centralidade, intensidade e velocidade das operações (PAULILLO, 2002).

Marchi e Wittmann (2008, p. 9) consideram que um bom nível de conexões sociais entre os atores que compõem a rede pode melhorar o fluxo de informações e promover uma forte coesão entre os membros da rede. Dessa forma, questões sociais e comportamentais seriam preditoras da coesão. Para analisar o desempenho de redes, os autores utilizam diferentes variáveis sociocomportamentais, relativas a comprometimento (engajamento e compromisso com acordos), confiança (dimensão externa e dimensão interna), cooperação (ajuda mútua e rotulagem) e conexões (externas e internas).

Nesse mesmo sentido, Jones, Hesterly e Borgatti (1997) argumentam que o uso de alguns mecanismos sociais contribui para uma boa coordenação na governança em rede entre empresas. Os mecanismos são: acesso restrito às transações; macrocultura; sanções coletivas e reputação. $O$ acesso restrito às transações reduz custos de coordenação ao desenvolver protocolos de comunicação e estabelecer rotinas de interação continuada, ao mesmo tempo em que aumenta a interação entre as partes e eleva o comprometimento. A macrocultura reduz custos de coordenação ao criar convergência de expectativas pela socialização e estabelecer linguagem comum e regras tácitas de comportamento. As sanções coletivas aumentam os custos de transgressão, diminuem custos de monitoramento e promovem incentivos para selecionar parceiros. Já a reputação dissemina informações sobre comportamento entre as partes.

A partir do referencial teórico acima exposto, foi montado um roteiro de entrevista para a pesquisa de campo, que permitiu avaliar a coesão e aspectos de coordenação de cada caso para, em seguida, analisar a efetividade de cada grupo em atingir seus objetivos. O Quadro 1 agrupa os indicadores usados para avaliar a coesão. Esses fatores abordam tanto as atitudes e comportamentos dos indivíduos quanto as interações entre eles.

\section{Metodologia}

O trabalho de campo foi composto por duas etapas. A primeira delas, de cunho exploratório, de modo a refinar o instrumento de coleta de dados para a etapa posterior, foi constituída por análise de documentos e por entrevista semiestruturada. A análise de documentos

Quadro 1. Indicadores para análise da coesão.

\begin{tabular}{|l|}
\hline \multicolumn{1}{|c|}{ Indicadores } \\
\hline Mecanismos formais/informais de coordenação \\
\hline Comprometimento dos associados \\
\hline Fatores de aglutinação \\
\hline Monitoramento e punição \\
\hline Cooperação e competição \\
\hline Individualismo e oportunismo percebidos \\
\hline Confiança \\
\hline Reputação \\
\hline Frequência das transações \\
\hline Tomada de decisões \\
\hline Relacionamento entre associados \\
\hline Atitude dos associados \\
\hline Tempo da relação \\
\hline Fluxo de informações \\
\hline Conexões externas \\
\hline
\end{tabular}


compôs-se de um acompanhamento do clipping de notícias Brasil Agro, especializado no setor sucroalcooleiro, que traz notícias de Valor Econômico, Folha de S. Paulo, Estado de S. Paulo, Jornal da Cana e outros órgãos especializados. Foram seguidos alguns passos para a realização dessa análise documental: recebimento diário do clipping de notícias por e-mail; seleção, a partir de títulos e subtítulos, para arquivamento daquelas que apresentam dados mais relevantes sobre o setor, compondo, ao final, um banco de aproximadamente 260 notícias; leitura das notícias e elaboração de fichamento com as informações diretamente relacionadas à temática do trabalho. Esta etapa teve início em fevereiro de 2008 e continuou a conclusão do trabalho, em setembro de 2011.

A entrevista semiestruturada foi realizada por telefone em fevereiro de 2009, com um analista estratégico de um dos grupos de comercialização atuantes na região Centro-Sul. Após análise das informações e surgimento de dúvidas, duas outras entrevistas foram realizadas com a mesma pessoa, em março de 2009, desta vez por e-mail. Esta estratégia segue as orientações de Gondim e Lima (2006), segundo os quais é recomendável, para pesquisas que incluem trabalho de campo, realizar um trabalho empírico preliminar, com análises sobre a instituição, o grupo ou as pessoas que se quer estudar.

Encerrada a etapa exploratória, a segunda etapa do trabalho foi composta por um estudo de casos múltiplos, utilizando a abordagem qualitativa, de modo a permitir melhor concepção das realidades organizacionais e maior proximidade com o fenômeno estudado (BRYMAN, 1989). Segundo Bebensat et al. (1987 apud VOSS, TSIKRIKTSIS e FROHLICH, 2002), uma das forças do estudo de caso é permitir que o fenômeno seja estudado em seu contexto natural e significante.

Foram três os casos analisados. Por caso entende-se o grupo de comercialização e sua rede composta pelas usinas associadas. A coleta de dados foi feita por entrevistas em profundidade, realizadas presencialmente. No total, foram 13 entrevistas. No caso A (os grupos não serão identificados para garantir o sigilo dos respondentes), foi entrevistado o diretor executivo da empresa que coordena o grupo, além de superintendentes de duas usinas associadas. No caso B, foram entrevistados o diretor executivo e o gerente de planejamento da coordenadora, além de três entrevistas com gerentes comerciais e analista de mercado de dois grupos industriais (empresas com mais de uma unidade sucroalcooleira) associados. No caso C, foram entrevistados o diretor de comunicação da coordenadora e o supervisor comercial e o gerente de compras de uma associada. Como alguns fatores influenciadores da coesão, tais como confiança, cooperação e comprometimento, são de difícil externalização pelos respondentes, ao final era aplicado um questionário em que o respondente deveria assinalar, em escala de quatro pontos (de muito fraco a muito forte), para diversas afirmações, o grau em que esses elementos estavam presentes. Por fim, as informações foram confrontadas por meio de três entrevistas com profissionais do setor de distribuição e que negociam com o setor de produção de etanol. Também foram avaliados relatórios e informativos das usinas e coordenadoras dos grupos. Essa etapa de coleta de dados, composta pelas entrevistas e análise de relatórios e informativos, ocorreu entre os meses de dezembro de 2010 e agosto de 2011.

\section{Resultados e discussão}

O caso A, comparativamente aos demais estudados, é o que tem menor número de associados. Mesmo assim, o número de membros mais do que dobrou desde sua fundação. Formado por unidades de menor escala e, em geral, independentes (que não participam de grupos industriais), o grupo perdeu alguns associados entre 2010 e 2011, pelo fato de alguns de seus associados terem sido adquiridos por corporações associadas a outros grupos. Um número considerável de empresas, dentre as fundadoras, fazia parte de uma associação de produtores de cachaça, o que contribuiu para a 
aglutinação dos seus membros. Laços pessoais também são fortes, sendo comum que associados atraiam para o grupo outras empresas com quem têm relações próximas. Decisões de quando vender, quanto vender, a que preço, qual produto (hidratado ou anidro) e sob qual forma (contrato ou spot) é da usina, que, para subsidiar essas decisões, elabora estudos de mercado, mantém contato telefônico diário com as associadas e faz reunião semanal em sua sede, para a qual são convidadas todas as empresas. As usinas, que devem realizar as vendas exclusivamente via grupo, pagam corretagem à coordenadora. Como há monitoramento da produção das usinas, essa corretagem é paga mesmo quando as usinas vendem por fora da coordenadora, o que funciona como mecanismo de punição. Essas questões são estabelecidas contratualmente quando da adesão ao grupo; no entanto, percebeu-se que, por vezes, usinas passam a participar do grupo sem ter a relação formalizada contratualmente.

O caso B, comparativamente aos outros dois estudados, apresenta o maior número de associados. Fazem parte dele grandes grupos industriais, o que resultou em crescimento substancial do número de associados nos últimos anos, sobretudo, motivado por processos de fusão e aquisição e por novas unidades implantadas por essas corporações. Os fundadores do grupo foram, à época da desregulamentação, fomentadores do processo de criação da BBA/Brasil Álcool. Dessa forma, sempre desempenharam papéis de liderança no setor sendo, inclusive, interlocutores em negociações do setor junto ao poder público. Esse status dos fundadores foi importante para a aglutinação e crescimento do grupo. A decisão de venda é das usinas, sendo que a coordenadora, como no caso A, elabora estudos de mercado, faz contatos frequentes com as associadas e promove reuniões semanais entre os membros do grupo. Como no caso A, há contrato de exclusividade das vendas, que devem ser realizadas todas via coordenadora do grupo. Assim, mesmo que vendam diretamente a distribuidoras, a corretagem deve ser paga. Por fim, ressalta-se que os contratos de associação devem ser renovados a cada safra.
O grupo do caso C é o mais antigo dentre os estudados. A empresa coordenadora do grupo constitui hoje uma sociedade anônima, que, além de realizar as vendas, tem estrutura logística composta por terminais portuários e escritórios internacionais. Destoando dos outros dois casos estudados, neste grupo a decisão de venda (que não se limita a etanol, mas também açúcar e energia) é da coordenadora que, por isso, garante à associada um fluxo de caixa constante, já que os pagamentos às usinas são feitos de maneira contínua, com preços referenciados à média dos últimos 12 meses do Indicador CEPEA/ESALQ. Como a coordenadora normalmente consegue vender com ágio sobre o Indicador, ao final do ano há uma distribuição do lucro às associadas (obtido também mediante as demais operações da coordenadora que, inclusive, presta serviços a empresas não associadas). Pelo fato de proporcionar um fluxo de caixa constante às associadas, a coordenadora também pode participar nos seus processos de obtenção de financiamentos de giro, sendo corresponsável dentro de limites previamente autorizados. Como a decisão de venda é da coordenadora, há menor fluxo de informações da coordenadora para as associadas e também entre as usinas, já que reuniões são realizadas apenas esporadicamente. Há forte presença contratual no grupo, já que os contratos têm duração mínima de 10 anos e a associação só pode ser encerrada cinco anos após a solicitação de rescisão.

Embora não saibam quantificar a elevação dos preços pagos às usinas propiciada pela existência dos grupos de comercialização, tanto usinas quanto coordenadoras afirmam que os grupos são bem-sucedidos na tarefa de melhorar o poder de barganha com as distribuidoras. As distribuidoras confirmam essa informação, ao citar que a formação dos grupos fragiliza a posição do comprador (no caso, as distribuidoras) nas negociações, por reduzir a pulverização na oferta do combustível. Além disso, outro fator determinante do poder é a habilidade dos jogadores e, nesse sentido, a mesa comercial de um grupo de comercialização é mais especializada e qualificada do que os funcionários de um 
departamento comercial de uma usina. Por fim, a coordenação dos atores dentro dos grupos, evitando a desestruturação total do setor, também é capaz de elevar o poder de barganha, conforme previa Marino e Azevedo (2003).

Apesar de possibilitar a obtenção de preços melhores e condições de pagamento mais favoráveis, as usinas afirmam que dificilmente há controle e planejamento efetivo sobre a quantidade ofertada de etanol, já que a decisão de venda (exceção do caso C) é das usinas e são poucas as que têm fôlego financeiro para segurar a venda até a entressafra.

Ao se analisar a coordenação dentro dos grupos, no caso A, dentre os mecanismos sociais de redes listados por Jones, Hersterly e Borgatti (1997, p. 926), o mais relevante é a macrocultura, já que foram observadas regras de comportamento tácitas e compartilhadas e convergência de expectativas. Isso é obtido tanto pelo histórico de associação de alguns membros quanto pela socialização promovida pela direção. No caso B, porém, a reputação dos seus membros tem maior importância. A aproximação entre os similares, nesse caso, tinha como critério principal o prestígio e o poder das usinas associadas, fatores que, porém, fazem com que usinas de menor volume acabem ficando à margem de algumas decisões. Já no caso C, as sanções são mais relevantes, com grande rigor jurídico, que dificultam, inclusive, a saída de membros, conforme será discutido de forma mais aprofundada a seguir.

Voltando aos mecanismos sociais listados por Jones, Hersterly e Borgatti (1997) para a governança em rede, há acesso restrito às transações nos casos $\mathrm{A}$ e $\mathrm{B}$, mas não no $\mathrm{C}$. $\mathrm{O}$ acesso restrito ocorre nos dois primeiros casos pelo fato de que as empresas que coordenam os grupos prestam serviços somente aos seus associados. Poucas exceções ocorrem no caso A, que chega a atender outras empresas, mas somente como experiência, para atrair novos membros. Esse acesso restrito eleva o comprometimento e a identificação dos associados. No caso C, o comprometimento é obtido pelos benefícios proporcionados pelo grupo, especialmente no que se refere à garantia de fluxo de caixa, além da presença forte da questão contratual.

Com relação às sanções coletivas, nos casos A e B há a obrigatoriedade de pagamento de corretagem sobre o volume produzido e não sobre a venda realizada via grupo, reduzindo, assim, o estímulo à prática de vendas por fora do grupo, que é o descumprimento de acordos mais frequente dentro desses grupos de comercialização. Essa sanção acaba até reduzindo os custos de monitoramento, visto que se pode fazer esse acompanhamento da produção por meio de dados do Ministério da Agricultura. No caso C, não foram constatadas vendas por fora, talvez pelo rigor jurídico da relação e pelo rigoroso monitoramento, tanto por sistema de informação quanto por visita periódica de auditores.

A respeito da formação dos grupos, cabe destacar que, no início, ela tinha objetivos mercadológicos (melhorar as condições de venda, o que inclui os preços), mas seguia também critérios relacionais. Com o crescimento dos grupos, porém, por meio da adesão de novas usinas, os aspectos relacionais, embora ainda existam (uma vez que a indicação junto a conhecidos continua sendo relevante para a atração de novos membros), deixam de ser o critério primordial. Isso traz maior dificuldade para a coordenação. Para solucionar esse problema, os grupos buscam submeter a entrada de novos associados à aprovação dos atuais membros. Além disso, a coordenadora exerce um papel importante em passar ao novo membro o comportamento esperado pelo grupo, especialmente no caso A, em que a cultura exerce papel mais importante que normas jurídicas no comportamento dos atores. Nos casos B e C, é preciso, ainda, que a usina adquira uma cota de capital da empresa coordenadora do grupo.

No Quadro 2 é possível conferir, de maneira comparativa, os fatores influenciadores da coesão em rede dos grupos de comercialização de etanol estudados. Discutem-se, a seguir, as principais diferenças entre os casos. Desde já, chama-se a atenção para as diferenças com relação ao engajamento, ao fator aglutinador, à formalidade da relação, ao fluxo de informações e às vendas. 
Quadro 2. Fatores influenciadores da coesão nos Grupos de Comercialização

\begin{tabular}{|c|c|c|c|}
\hline Fatores & Caso A & Caso B & Caso C \\
\hline Engajamento & $\begin{array}{l}\text { Atores engajados, com partici- } \\
\text { pação média em reuniões. }\end{array}$ & $\begin{array}{l}\text { Atores engajados, com partici- } \\
\text { pação média em reuniões. }\end{array}$ & $\begin{array}{l}\text { Atores engajados, mas com } \\
\text { baixa interação entre eles. }\end{array}$ \\
\hline $\begin{array}{l}\text { Interesse em aprofundar } \\
\text { a relação }\end{array}$ & Alto. & Alto. & Alto. \\
\hline Entrada/saída de membros & $\begin{array}{l}\text { Ações, inclusive de associados, } \\
\text { para captar novos membros e } \\
\text { evitar a saída. }\end{array}$ & $\begin{array}{l}\text { Ações para captar novos } \\
\text { membros e evitar a saída. Parti- } \\
\text { cipação exige cota. }\end{array}$ & $\begin{array}{l}\text { Ações para captar novos } \\
\text { membros e alta barreira à } \\
\text { saída. Participação exige cota. }\end{array}$ \\
\hline Fator aglutinador & $\begin{array}{l}\text { Identidade comum entre os } \\
\text { membros. }\end{array}$ & $\begin{array}{l}\text { Prestígio dos associados. Grupo } \\
\text { tem marca forte. }\end{array}$ & $\begin{array}{l}\text { Garantia de fluxo de caixa. } \\
\text { Grupo tem marca forte. }\end{array}$ \\
\hline Formalidade da relação & $\begin{array}{l}\text { Média, sem controle rigoroso } \\
\text { de contratos. Regras tácitas de } \\
\text { conduta. }\end{array}$ & $\begin{array}{l}\text { Alta. Contratos, revistos e } \\
\text { estabelecidos a cada nova safra, } \\
\text { têm questões relacionais. }\end{array}$ & $\begin{array}{l}\text { Alta. Contratos de longa dura- } \\
\text { ção e que abordam questões } \\
\text { relacionais. }\end{array}$ \\
\hline Compromisso com acordos & $\begin{array}{l}\text { Médio a alto; ocorre venda por } \\
\text { fora do grupo. }\end{array}$ & $\begin{array}{l}\text { Médio a alto; ocorre venda por } \\
\text { fora do grupo. }\end{array}$ & Alto. \\
\hline Sanções & $\begin{array}{l}\text { Obrigatoriedade de pagamento } \\
\text { de corretagem independente de } \\
\text { a venda ser realizada via grupo }\end{array}$ & $\begin{array}{l}\text { Obrigatoriedade de pagamento } \\
\text { de corretagem independente } \\
\text { de a venda ser realizada via } \\
\text { grupo }\end{array}$ & $\begin{array}{l}\text { Monitoramento e rigidez } \\
\text { contratual inibem atitudes } \\
\text { oportunistas. }\end{array}$ \\
\hline Confiança & $\begin{array}{l}\text { Elevada na direção do grupo e } \\
\text { entre os associados. }\end{array}$ & $\begin{array}{l}\text { Elevada na direção do grupo e } \\
\text { entre os associados. }\end{array}$ & $\begin{array}{l}\text { Elevada na direção do grupo e } \\
\text { média entre os associados. }\end{array}$ \\
\hline Rotulagem & $\begin{array}{l}\text { Baixo oportunismo e individua- } \\
\text { lismo percebidos. }\end{array}$ & $\begin{array}{l}\text { Baixo oportunismo e individua- } \\
\text { lismo percebidos. }\end{array}$ & $\begin{array}{l}\text { Médio oportunismo e indivi- } \\
\text { dualismo percebidos. }\end{array}$ \\
\hline $\begin{array}{l}\text { Ações de cooperação e } \\
\text { investimentos conjuntos }\end{array}$ & $\begin{array}{l}\text { Consolidação de lotes, troca de } \\
\text { experiências, pool para diesel. } \\
\text { Investimentos conjuntos no pas- } \\
\text { sado. }\end{array}$ & $\begin{array}{l}\text { Troca de experiências, pool para } \\
\text { diesel, aluguel de tanques, com- } \\
\text { partilhamento de cargas. Inves- } \\
\text { timentos conjuntos no passado. }\end{array}$ & $\begin{array}{l}\text { Troca de experiências, pool } \\
\text { para diesel e sacarias. Inves- } \\
\text { timentos elevados da coorde- } \\
\text { nação do grupo em logística. }\end{array}$ \\
\hline $\begin{array}{l}\text { Reputação junto a atores } \\
\text { externos }\end{array}$ & Média. & Alta. & Alta. \\
\hline $\begin{array}{l}\text { Tempo de relação e } \\
\text { vínculos anteriores } \\
\end{array}$ & $\begin{array}{l}\text { Médio. Associação de produto- } \\
\text { res de cachaça. }\end{array}$ & $\begin{array}{l}\text { Médio. Relações informais de } \\
\text { liderança no setor. }\end{array}$ & Longo. \\
\hline $\begin{array}{l}\text { Frequência de transações } \\
\text { entre associados e } \\
\text { coordenadora }\end{array}$ & $\begin{array}{l}\text { Média. Usinas de menor porte, } \\
\text { com menor atuação no mercado. }\end{array}$ & $\begin{array}{l}\text { Alta. Usinas, em geral, de maior } \\
\text { porte, com grande volume. }\end{array}$ & $\begin{array}{l}\text { Alta, mas puramente opera- } \\
\text { cional. Usinas de maior porte, } \\
\text { com grande volume. }\end{array}$ \\
\hline Fluxo de informações & $\begin{array}{l}\text { Alto. Acesso restrito aos mem- } \\
\text { bros do grupo. }\end{array}$ & $\begin{array}{l}\text { Alto. Acesso restrito aos mem- } \\
\text { bros do grupo. }\end{array}$ & $\begin{array}{l}\text { Baixo. Serviços são prestados } \\
\text { também a empresas de fora do } \\
\text { grupo. }\end{array}$ \\
\hline Vendas & $\begin{array}{l}\text { Spot e contratos de longo prazo; } \\
\text { Restritas ao etanol. Decisão é da } \\
\text { usina. }\end{array}$ & $\begin{array}{l}\text { Spot e contratos de longo } \\
\text { prazo, com predomínio dos } \\
\text { últimos; Restritas ao etanol. } \\
\text { Decisão é da usina. }\end{array}$ & $\begin{array}{l}\text { Spot e contratos de longo } \\
\text { prazo, com predomínio dos } \\
\text { últimos; Etanol, açúcar e } \\
\text { subprodutos. Decisão é do } \\
\text { grupo. }\end{array}$ \\
\hline Conexões externas & Redundantes. & Redundantes. & Relevantes. \\
\hline
\end{tabular}

De maneira geral, há comprometimento por parte dos associados, que têm uma atitude positiva diante dos grupos, o que é um indicador de boa coesão. Um reflexo dessa coesão, conforme teoria de Friedkin (2004), está na baixa taxa de turn over e no interesse de fortalecer a relação, ainda que haja, dentro dos grupos, subgrupos de empresas mais ou menos engajadas, o que se reflete na frequência às reuniões, que não é uniforme entre todos os associados. Como foi colocado por Powell e Smith-Doerr (1994), quando está presente o desejo de manter ou fortalecer a associação, as pessoas estão mais dispostas a cooperar. Cooperação essa que se manifesta, dentro dos grupos, principalmente na troca de informações entre os associados, 
sobre questões que extrapolam a esfera comercial e entra em experiências sobre processos e tecnologias industriais e agrícolas. No caso C, embora haja algumas ações cooperativas $\mathrm{e}$ um alto interesse de aprofundar a relação das usinas com a coordenadora do grupo, há pouca interação entre os associados, já que a ocorrência de reuniões entre associados é baixa.

No caso A, a origem e a identidade comum, além dos valores compartilhados, são aspectos relevantes para a coesão, que contribuem para a aglutinação das usinas. São membros que tinham experiência anterior de associação e se enxergam como iguais, pelo fato de as usinas terem porte equivalente (no caso, pequeno porte). No caso B, o status, a reputação e o poder dos associados foram fundamentais na criação do grupo, formado inicialmente por muitas grandes empresas. O crescimento do grupo também foi ancorado na aquisição de novas usinas por parte desses associados de maior poderio econômico. Já no caso $C$, também formado por usinas de maior poderio, embora o tempo de relação seja longo, há baixa interação entre os associados. Assim, no grupo $\mathrm{C}$, mais do que fatores relacionais, $\mathrm{o}$ mais importante para a atração e manutenção de associados está no respaldo financeiro oferecido pela coordenadora.

Dentro dos grupos, entre os associados, percebeu-se que a cooperação é maior do que a competição. A competição, quando existe, é muito mais reputacional entre usineiros do que concorrencial entre empresas. Explica-se: o fato de se trabalhar com produtos que são commodities, sem possibilidade de diferenciação de produto, faz com que a maioria das usinas não se perceba como concorrente na disputa por parcelas de mercado. Por outro lado, alguns usineiros querem ser mais reconhecidos do que outros, seja por moagens recordes, seja pela implantação de novas unidades. Dessa forma, buscam posições de destaque, que lhes gerem reputação no setor. É assim que a competição mais se manifesta entre os associados. Já a cooperação manifesta-se, sobretudo, sob a forma de troca de experiência entre usinas, que é menor no caso $C$ do que nos demais, em virtude da pouca frequência de reuniões. Por sua vez, o grupo $\mathrm{C}$ possui elevados investimentos conjuntos, o que, porém, só é viabilizado pelo papel pró-ativo empreendido pela coordenadora do grupo como unidade de negócio. Ou seja, os investimentos conjuntos não decorrem de acordos diretos entre usinas, mas da coordenadora, que possui grandes ativos logísticos, que são usados, inclusive, para prestar serviços também a empresas de fora do grupo.

A competição entre os grupos acontece no sentido de se conquistar novos associados, embora diretores das empresas coordenadoras e usinas associadas concordem que é melhor uma usina participar de qualquer grupo (mesmo que não o próprio) do que não participar, pois, assim, há maior consolidação da oferta. $O$ grupo $C$ foi o que, nas entrevistas, mais demonstrou espírito de competição com outros grupos. As próprias distribuidoras reconhecem que o grupo C, pelo fato de oferecer um respaldo, além de comercial, financeiro e de infraestrutura logística para as usinas, tem conquistado associados de outros grupos.

Apesar disso, observa-se que benefícios financeiros e logísticos não operam sozinhos como fatores determinantes da escolha de um ou outro grupo. O sentido de pertencimento, com forte vínculo entre os membros, como constatado no caso A, é importante para a permanência das empresas em algum grupo, superando, às vezes, serviços adicionais que possam ser oferecidos por outro grupo. Esse sentido de pertencimento é um elemento importante para manter o grupo coeso e estabelecer bases de confiança.

Por falar em confiança, dentre os fatores sociocomportamentais para análise de redes listados por Marchi e Wittmann (2004), com destaque, nos grupos A e B, para a confiança, entre os associados e desses para com a coordenadora do grupo, visto que mesmo entre aqueles membros que apresentaram baixo grau de confiança interna, ou seja, que normalmente desconfiam das pessoas, a confiança no grupo de comercialização foi elevada. Apesar de algumas atitudes oportunistas, como se discutirá a seguir, nenhum dos entrevistados desses grupos rotulou 
os demais associados como oportunistas ou individualistas. No caso C, por sua vez, embora haja confiança elevada na coordenação do grupo, a confiança percebida é apenas média entre os associados, resultado, provavelmente, da baixa interação entre eles. Da mesma forma, no caso C, houve casos de rotulação de associados como oportunistas e individualistas.

Com impacto negativo sobre a coesão de alguns grupos, constatou-se que há, embora não corriqueiros, casos de conflito de agência entre proprietários e executivos das usinas, com comportamentos oportunistas por parte desses últimos. Explica-se: alguns executivos de usinas posicionam-se contra a participação no grupo de comercialização, temendo perder status e visibilidade no setor, pelo fato de não negociar mais diretamente com as distribuidoras. Com esse afastamento do mercado, podem ainda perder vantagens financeiras, visto que alguns corretores independentes repassam ao executivo, extraoficialmente, parte de sua comissão para que sejam privilegiados em transações. Assim, quando presente, essa atitude oportunista do executivo representa uma barreira ao crescimento e à coesão do grupo, pois ele boicota-o e cria, junto ao proprietário, boatos de que a usina é preterida nas vendas em detrimento de outros associados do grupo.

É importante trabalhar para manter a coordenação e a coesão nos grupos, pois problemas nesses sentidos prejudicam o conjunto dos associados. As distribuidoras enxergam que há diferenças nas negociações com os diferentes grupos. Há aqueles grupos que são melhor coordenados e, por isso, têm mais poder e conseguem preços maiores na negociação. Destaca-se, nesse ponto, o caso $C$, pelo fato de agregar toda a oferta dos seus associados e ter a decisão de venda. Isso evita, inclusive, a venda de algumas usinas por fora do grupo de comercialização que, como corroborado pelas distribuidoras, não é fato tão raro nos demais grupos.

Conforme já citado, essa venda dos associados por fora dos grupos de comercialização, não cumprindo os contratos de associação, envia sinais distorcidos ao mercado. Se para as usinas é negativo, pelo fato de puxar os preços para baixo (uma vez que um mesmo lote pode ser ofertado duas vezes no mercado, passando-se a imagem de oferta maior do que a real), para as distribuidoras isso tem duas vertentes: de um lado, pode possibilitar a obtenção de compras com menor custo; por outro, pode significar uma vantagem para a distribuidora concorrente e não para ela. Assim, durante as entrevistas, uma das distribuidoras afirmou que, para as grandes distribuidoras, a coordenação e a coesão dos grupos pode ser positiva, visto que, pelo fato de trabalharem com grandes estoques, movimentos bruscos do mercado (quando ofertas não previstas são realizadas, derrubando o preço do etanol) podem significar desvantagens competitivas diante de distribuidoras concorrentes.

$\mathrm{O}$ combate à venda por fora, por parte dos grupos de comercialização, é realizado principalmente pela obrigatoriedade da usina em pagar corretagem sobre seu volume produzido, independentemente de a venda ter sido realizada pelo grupo. Essa é uma forma de punição aplicada aos associados que descumprem o acordo de exclusividade de venda. Esse descumprimento é mais frequente no grupo A que no grupo B, fato comprovado até pelas distribuidoras. Isso faz com que a reputação da coordenadora do grupo $\mathrm{A}$ no mercado, embora não baixa, seja inferior à reputação dos demais grupos. No grupo C, não foi constatado descumprimento de acordos, com vendas por fora do grupo. O maior rigor jurídico e os mecanismos de monitoramento mais constantes, com sistemas de informação e visitas mensais de auditores, contribuem pra isso.

Essa melhor coordenação no caso C, porém, não significa que ele seja o mais coeso, pois se percebe nele menor interação, cooperação e confiança entre os associados. Fatores contratuais e econômicos são mais importantes para manter a coordenação deste grupo. Nos casos A e B, por sua vez, fatores relacionais estão mais presentes, aumentando o sentido de pertencimento, a cooperação, a identidade comum, o que significa maior coesão entre os associados. 
Vale destacar, porém, que a maior parte dos respondentes afirmou que a cooperação seria fraca se não houvesse a obtenção de benefícios diretos no curto prazo. Assim, a sobrevivência dos grupos de comercialização está ligada à capacidade de agregar valor aos associados, principalmente pela melhora nas condições de venda do etanol. Alguns grupos, no entanto, não têm se limitado à comercialização, estudando outras formas de agregar valor, seja trabalhando também com a venda de açúcar e energia, seja criando estruturas logísticas. No caso C, este modelo de atuação já está implantado e pode ser uma tendência para os demais grupos. Desta forma, evitar-se-ia a estagnação e rigidez da rede que, conforme Assens (2003), provoca a saída de alguns membros.

Como aspecto negativo dos grupos, vale citar que a maior parte dos respondentes considera que há limitações nas conexões externas que os grupos proporcionam, principalmente pela redundância dessas conexões, ou seja, os elos externos dos membros do grupo costumam ser comuns aos dos demais membros. Dessa forma, se por um lado a coesão, facilitada a partir de membros com afinidades entre si, possibilita melhor coordenação, de outro, inibe inovações ou o surgimento de outras oportunidades de negócio. Exceção, mais uma vez, é o caso $C$, em que as conexões externas foram consideradas mais relevantes.

Conforme Azevedo (2000, 2001), a formação de grupos é uma alternativa à oligopsonia normalmente presente na agroindústria, mas que enfrenta grandes custos ex-post, com dificuldades na coordenação. Os grupos de comercialização de etanol estudados, porém, vêm conseguindo superar esses desafios, já que são iniciativas com mais de 10 anos e que vêm atraindo novos associados. Esses associados chegam em busca de melhorar as condições de negociação para a venda, de acesso a valiosas informações de mercado e de troca de experiências com outras usinas. Embora os problemas de coordenação existam, os grupos trouxeram, do ponto de vista das usinas, mais estabilidade ao setor. Cada qual com sua história e diferentes mecanismos sociais usados para construir a coordenação e a coesão, eles podem ser considerados bem-sucedidos na tarefa de trazer equilíbrio às transações indústria-distribuição do setor sucroalcooleiro.

\section{Conclusões}

Como foi visto ao longo do artigo, um dos reflexos principais da desregulamentação do setor sucroalcooleiro foi a criação, por parte das usinas, de grupos de comercialização de etanol. A primeira iniciativa, a BBA/Brasil Álcool, foi criada com o objetivo de enxugar estoques e recuperar os preços do etanol pago às usinas. Dissolvida por decisão do Cade e por problemas de coordenação entre as usinas associadas, a experiência, porém, serviu de inspiração para a criação de outros grupos, desta vez com número menor de membros.

Desta forma, este estudo teve como objetivo analisar a coordenação e a coesão de grupos de comercialização de etanol atuantes na região Centro-Sul do Brasil. Como método de pesquisa, realizou-se um estudo múltiplo de casos, com três dos quatro grupos de comercialização atuantes na região Centro-Sul, com coleta de dados por meio de análise de documentos e entrevistas em profundidade.

Antes de continuar as considerações finais, é preciso esclarecer que não se advoga, aqui, em favor dos grupos de comercialização como forma de incrementar resultados econômicos para as usinas. O que se faz é mostrar como a coordenação dos grupos como rede pode ser construída e os mecanismos usados por eles para manter a coesão. Ao conseguir isso, os grupos contribuem para equilibrar o jogo de forças, o que traz maior estabilidade para a cadeia do etanol e seu sucesso frente a outras fontes de energia. Como discorrido ao longo da fundamentação teórica, a eficiência de um sistema produtivo não resulta somente da solução de problemas de produção. A eficiência de um sistema produtivo depende também de quão bem se resolvem os problemas 
de transação, as relações entre compradores e vendedores. Da mesma forma que preços elevados são prejudiciais ao consumidor, os preços baixos do período pós-desregulamentação eram prejudiciais às usinas, com riscos de falência do setor, o que seria, posteriormente, igualmente prejudicial ao consumidor final.

Conseguiu-se avançar, nesse trabalho, na discussão da coesão em redes de empresas, com referências buscadas não só na Sociologia Econômica, mas também nas Ciências Sociais. A partir desses indicadores, os grupos estudados foram considerados coesos, o que é evidenciado sobretudo pela atitude positiva das usinas diante do grupo e pelo desejo de fortalecimento da participação. Se considerada a racionalidade limitada dos agentes, ou seja, a impossibilidade de contratos que esgotem todas as possibilidades, e as turbulências do ambiente institucional, o engajamento dos associados é fundamental para evitar problemas gerais de oportunismo e, assim, manter a coesão. Ressalta-se, porém, que embora o grupo $\mathrm{C}$ seja o que as atividades sejam melhor coordenadas, pelo fato de a decisão de venda estar na mão da coordenadora do grupo, os grupos A e B podem ser considerados mais coesos no que se refere à interação, confiança, cooperação e sentido de pertencimento entre os associados. Isto é possibilitado sobretudo pelas reuniões semanais das quais participam associados e coordenadora de cada grupo.

Os grupos, por meio de coordenação e coesão em rede, permitem uma melhora no poder de barganha junto às distribuidoras de combustível, trazendo maior equilíbrio à relação comercial. Isto é evidenciado considerando-se que o poder de mercado de uma empresa (ou grupo de empresas) está relacionado principalmente com sua capacidade de controlar o preço do produto. Nesse estudo, ficou clara a capacidade dos grupos de comercialização de influenciar as cotações do etanol, seja pelo volume comercializado, seja pelo aumento da racionalidade (com uma venda mais técnica), seja pela redução da assimetria de informações (que pendia a favor das grandes distribuidoras).
A carência de fontes naturais de confiança no setor sucroalcooleiro, com seu histórico de baixa reputação dos atores, constituía-se em obstáculo para a concretização dos grupos de comercialização. Observou-se, porém, que, mesmo com a existência de problemas de coordenação, em alguns casos com associados não respeitando a exclusividade da venda via grupo, de maneira geral, os membros são comprometidos com o propósito dos grupos. Embora os grupos (com exceção do caso C, em que associados delegam a decisão de venda), não sejam capazes de controlar e planejar estoques, a atuação no mercado, de modo a construir preço, sinalizando valores que impulsionem o Indicador CEPEA/ESALQ (enquanto distribuidoras puxam-no para baixo), é positiva às usinas. Com esse benefício direto e com o aumento na frequência das transações, é reduzido o incentivo a atitudes oportunistas por parte das usinas.

Como limitação do trabalho, é preciso citar o fato de não se trabalhar, dentro de cada grupo, com uma amostra representativa das usinas. Isso ocorreu devido à dificuldade em se conseguir a participação dos atores em estudos acadêmicos, fato característico do setor sucroalcooleiro. Para a realização de três estudos de caso (número relevante se considerado que há quatro grupos ativos na região Centro-Sul), foram necessários contatos com algumas dezenas de empresas, sendo negativa a resposta da maioria. Assim, pelo critério da conveniência, foram incluídos aqueles que se dispuseram a participar do estudo. Muitas entrevistas só foram possíveis a partir de contatos pessoais dos pesquisadores ou indicação de outros respondentes. É possível que essa predisposição em participar da pesquisa seja, justamente, característica de membros mais engajados com os grupos de comercialização.

Sugerem-se, para estudos futuros, pesquisas que abordem como a coesão e a coordenação serão trabalhadas nos grupos com os recentes processos de aumento da participação do capital internacional no setor e consolidação de acordos estratégicos de usinas com empresas petrolíferas. Conforme discutido na teoria, 
quanto mais heterogêneos os grupos, quanto mais os diferentes são obrigados a conviver, mais problemática se torna a coesão.

\section{Referências bibliográficas}

ASSENS, C. Le réseau d'entreprises: vers une synthèse des connaissances. Management International, v. 7, n. 4, p. 49-59, 2003.

AZEVEDO, P. F. Informação e barganha: implicações estratégicas em arranjos verticais. In: SEMINÁRIO BRASILEIRO DA NOVA ECONOMIA INSTITUCIONAL, 2, 2001, Campinas. Anais... Campinas: Instituto de Economia Unicampa, 2001.

AZEVEDO, P. F. Nova economia instuticional: referencial geral e aplicações para a agricultura. Revista Agricultura em São Paulo, v. 47, n. 1, p. 33-52, 2000.

BACCARIN, J. G. A constituição da nova regulamentação sucroalcooleira. São Paulo: Editora UNESP, 2005.

BIOAGÊNCIA. Associados. Disponível em <http:// www.bioagencia.com.br/usinas/index.php $>$. Acesso em: 30 set. 2010.

BRITTO, J. Cooperação interindustrial e redes de empresas. In: KUPFER, D.; HASENCLEVER, L (Org.). Economia Industrial: fundamentos teóricos e práticos no Brasil. 2. ed. Campus: Rio de Janeiro, 2002.

BRYMAN, A. Research methods and organization studies. London: Routledge, 1989.

CEPAL. Cohésion social: inclusión y sentido de pertenencia en América Latina y el Caribe. Santiago de Chile: Naciones Unidas, 2007.

COPERSUCAR. Unidades produtoras associadas. Disponível em: <http://www.copersucar.com.br/ hotsite/2010/localizacao.html> Acesso em: 20 set. 2010.

CPA. Acionistas. Disponível em: <http://www. cpatrading.com.br/site/?pg=empresa $>$ Acesso em: 25 set. 2010.

DOLNIKOFF, F. Contratos de etanol carburante $e$ racionalidade econômica da relação entre usinas $e$ distribuidoras de combustíveis no Brasil. Dissertação (Mestrado em Administração). Faculdade de Economia, Administração e Contabilidade da Universidade de São Paulo, São Paulo, 2008.

FARINA, E. et al. Mercado e concorrência do etanol. In: SOUZA, E. L.; MACEDO, I. C. (Org.). Etanol $e$ bioeletricidade: a cana-de-açúcar no futuro da matriz energética. São Paulo: LUC, 2010. p. 226-259.
FILGUEIRA, Fernando. Cohésion, riesgo y arquitectura de protección social en América Latina. Santiago de Chile: División de Desarrollo Social da CEPAL, 2007.

FRIEDKIN, N. E. Social Cohesion. Annual Review of Sociology, v. 30, p. 409-425, 2004.

GARCIA, L. M. Coesão relacional e mecanismos formais $e$ informais de coordenação em redes de supermercados de pequeno porte no estado de São Paulo. Tese (Doutorado em Engenharia de Produção), Universidade Federal de São Carlos, São Carlos, 2011.

GARGIULO, M.; BENASSI, M. Trapped in your own net?Network cohesion, structural holes and the adaptation of social capital. Organization Science, vol. 11, n. 2, p. 183-196, 2000.

GONDIM, L. M. P.; LIMA, J. C. A pesquisa como artesanato intelectual: considerações sobre método e bom senso. São Carlos: EdUFSCar, 2006.

JONES, C.; HERSTERLY, W.; BORGATTI, S. P. A general theory of network governance: exchange conditions and social mechanisms. Academy of Management Review, v. 22, n. 4, p. 911-945, 1997.

LARSON, A. Network dyads in entrepreneurial setting: a study of the governance of exchange relationships. Administrative Science Quarterly, v. 37, n. 1, p. 76-104, 1992.

LOPES, M. B. Análise dos canais de distribuição do etanol carburantebrasileiro: um estudo exploratório. Dissertação (Mestrado em Engenharia de Produção). Centro de Ciências Exatas e de Tecnologia, Universidade Federal de São Carlos, São Carlos, 2009.

MAPA. Relação das unidades produtoras cadastradas no departamento de cana-de-açúcar e agroenergia: posição 12 de julho de 2010. Disponível em <http://www.agricultura. gov.br/pls/portal/docs/PAGE/MAPA/SERVICOS/ USINAS_DESTILARIAS/USINAS_CADASTRADAS/ UPS_12-07-2010_0.PDF > . Acesso em: 14 jul. 2010.

MARCHI, J. J.; WITTMANN, M. L. Redes de empresas: uma análise das relações entre fatores sóciocomportamentais e desempenho competitivo. REAd, ed. 60, v. 14, n. 2, 2008.

MARINO, M. K.; AZEVEDO, P. F. Avaliação da intervenção do sistema brasileiro de defesa da concorrência no sistema agroindustrial da laranja. Revista Gestão \& Produção, v. 10, n. 1, p. 35-46, 2003.

MARJOTTA-MAISTRO, M. C.; BARROS, G. S. C. Relações comerciais e de preços no mercado nacional de combustíveis. In: CONGRESSO BRASILEIRO DE ECONOMIA E SOCIOLOGIA RURAL, 40, 2002, Passo Fundo. Anais... Brasília, SOBER, 2002. 
MELLO, F. O. T. As metamorfoses da rede de poder agroindustrial sucroalcooleira no estado de São Paulo: da regulação estatal para a desregulamentação. Dissertação (Mestrado em Engenharia de Produção) - Departamento de Engenharia de Produção, Universidade Federal de São Carlos, São Carlos, 2004.

MELLO, F. O. T. Formas plurais de governança no complexo agroindustrial citrícola: análise dos produtores de laranja da microrregião de Bebedouro/SP. Tese (Doutorado em Engenharia de Produção). Universidade Federal de São Carlos, São Carlos, 2008.

MELLO, F. O. T.; PAULILLO, L. F. O. Mudança institucional e reestruturação na rede agroindustrial sucroalcooleira paulista. In: CONGRESSO INTERNACIONAL DE ECONOMIA E GESTÃO DE REDES AGROALIMENTARES, 4, 2003, Ribeirão Preto. Anais... Ribeirão Preto, 2003.

MÉNARD, C. A new institutional approach to organization. In: MENARD, C.; SHIRLEY, M. (eds). Handbook of New Institutional Economics, p. 281-318, 2005.

MILANEZ, A. Y. et al. Logística para o etanol: situação atual e desafios futuros. BNDES Setorial, v. 31, p. 49-98, 2010.

MORI, J. S.; MORAES, M. A. F. D. Características do mercado do álcool anidro e hidratado e suas implicações para o mercado de combustíveis. In: CONGRESSO BRASILEIRO DE ECONOMIA E SOCIOLOGIA RURAL, 45, 2007, Londrina. Anais... Londrina: SOBER, 2007.

OLIVEIRA, N. Consumo de álcool cresce mais de $52 \%$ no primeiro semestre. Disponível em: <www.agenciabrasil.gov. br/noticias/2008/08/13/materia.2008-08-13.9355959074>. Acesso em: 17 out. 2008.

PAULILLO, L. F. O. As transformações da rede de poder citrícola brasileira. Revista Economia Ensaios, v. 16, p. 141-177, 2002.

PAULILLO, L. F. O. et al. Eficácia e coesão social do projeto viva leite : uma avaliação da rede de segurança alimentar de Osasco e Carapicuíba. Revista de Economia Agrícola, 56, p. 7-28, 2009.

PAULILLO, L. F. O.; VIAN, C. E. F.; MELLO, F. O. Autogestão, governança setorial e sustentatibilidade no complexo agroindustrial canavieiro no século 21 . Revista de PolíticaAgrícola, n. 1, p. 40-62, 2008.

POWELL, W. W.; SMITH-DOERR, L. Networks and economic life. In: SMELSER, N.; SWEDBERG, R. (Org.). Handbook of Economic Sociology. Princeton: Princeton University Press, 1994.

RELATÓRIO RESERVADO. Al Khallej Sugar refina associação com a Copersucar. Disponível em: <http:// www.brasilagro.com.br/index.php?noticias/visualizar_ impressao/12/33599 >. Acesso em: 11 fev. 2011.

SACOMANO NETO, M. Análise das redes: estrutura e relações. In: ENCONTRO NACIONAL DE ENGENHARIA DE PRODUÇÃO, 23, 2003, Ouro Preto. Anais... Ouro Preto, ENEGEP, 2003.

SACOMANO NETO, M.; TRUZZI, O. M. S. Configurações estruturais e relacionais de fornecedores: uma resenha compreensiva. Revista de Administração da USP, v. 39, n. 3, p. 255-263, 2004.

SAUVÉE, L. Towards an institutional analysis of vertical coordination in agribusiness. In: CONFERENCE IN VERTICAL COORDINATION IN THE FOOD SYSTEM, Washington, 1995. Proceedings...Washington, 1995.

SCA. Produtores. Disponível em <http://www.scalcool. com.br/portugues/empresa.asp > Acesso em: 30 set. 2010.

SILVA, C. L. M.; COSER, C. Rede de relações interorganizacionais no campo organizacional de Videira-SC. Revista de AdministraçãoContemporânea, v. 10, n. 4, out-dez. 2006.

UZZI, B. Social structure and competition in interfirm networks: the paradoxo of embeddedness. Administrativa Science Quarterly, v. 42, n. 1, p. 35-67, 1997.

VIAN, C. E. F. Agroindústria canavieira: estratégias competitivas e modernização. Campinas: Átomo, 2003.

VOSS, C.; TSIKRKTSIS, N.; FROHLICH, M. Case research in operations management. International Journal of Operatoins \& Production Management, v. 22, n. 2, p. 195-219, 2002.

ZYLBERSZTAJN, D. Estruturas de governança $e$ coordenação do agribusiness: uma aplicação da Nova Economia das Instituições. Tese (Livre Docência) - Faculdade de Economia, Administração e Contabilidade da Universidade de São Paulo, São Paulo, 1995. 
